\title{
Early life mental health and problematic drinking in mid-adulthood: evidence from two British birth cohorts
}

\author{
Ke Ning ${ }^{1}\left[\right.$. Praveetha Patalay ${ }^{1,2} \cdot$ Jennifer L. Maggs ${ }^{3} \cdot$ George B. Ploubidis $^{1}$
}

Received: 10 September 2020 / Accepted: 10 March 2021 / Published online: 25 March 2021

(c) The Author(s) 2021

\begin{abstract}
Purpose Accumulating evidence suggests that externalising problems are consistently associated with alcohol use behaviours, but findings are inconsistent regarding the role of internalising problems. We investigate whether externalising and internalising problems are associated with problematic drinking in mid-adulthood, and whether potential associations are modified by age, sex and cohort.

Methods The National Child Development Study (NCDS58, $n=17,633)$ and 1970 British Cohort Study (BCS70, $n=17,568)$ recruited new-borns in Great Britain in a single week in 1958 and 1970. Mental health was assessed with the Rutter Behaviour Questionnaire at ages 7,11, and 16 in NCDS58 and ages 5, 10 and 16 in BCS70. Problematic drinking was measured with the CAGE questionnaire at age 33 in NCDS58 and age 34 in BCS70, and the AUDIT scale at age 44/45 in NCDS58 and age 46 in BCS70. Latent scores of externalising and internalising problems were added chronologically into lagged logistic regression models.

Results Externalising and internalising problems were associated in opposite directions with problematic drinking in midadulthood. Externalising was a risk factor (OR [95\% CI] ranging from $1.06[1.03,1.10]$ to $1.11[1.07,1.15]$ for different ages), and internalising was a protective factor (OR [95\% CI] ranging from $0.95[0.92,0.99]$ to $0.90[0.86,0.94]$ for different ages). Associations between early life mental health and mid-adulthood problematic drinking did not differ by developmental timing but were stronger in males.

Conclusion Our study provides new insights on links of externalising and internalising difficulties with alcohol use and has implications for public policy in the UK.
\end{abstract}

Keywords Early life mental health · Adulthood problematic drinking · Developmental perspective $\cdot 1958$ National Child Development Study $\cdot 1970$ British birth cohort

\section{Introduction}

Alcohol contributes substantially to the global burden of disease, not only through alcohol use disorders (AUD) but also via other disease consequences resulting from alcohol use, such as injuries and suicide, cardiovascular disease and cancer [1]. Knowledge on the etiological mechanisms of

Ke Ning

ke.ning.16@ucl.ac.uk

1 Centre for Longitudinal Studies, UCL Social Research Institute, University College London, London, UK

2 MRC Unit for Lifelong Health and Ageing, University College London, London, UK

3 College of Health and Human Development, Pennsylvania State University, State College, USA problematic alcohol use is needed to inform the development of more effective interventions.

Theoretical and empirical research supports the idea that alcohol problems in adulthood have their roots in early life [2]. One longstanding hypothesis is that problematic drinking develops from early life externalising problems, defined broadly as aggression and disinhibited and antisocial behaviour [3, 4]. An alternative pathway involves internalising problems, which reflects difficulties with negative affect [5]. Epidemiological evidence regarding the associations between early life externalising and internalising problems and alcohol use behaviours in adulthood has been summarised in a recent systematic review [6]. In general, externalising problems in childhood and adolescence act as a risk factor for alcohol use/misuse in adulthood, while results are equivocal with respect to internalising problems 
in that positive [7-9], negative [10-13] and null associations [14-17] were all reported across studies.

A series of factors (developmental timing, sex, history, culture and adjustment of externalising or internalising problems accordingly) may contribute to the inconsistencies, but no definitive conclusions can be drawn as those factors were rarely examined within the same study [6]. Externalising and internalising problems are typically measured at one timepoint (mainly adolescence), which ignores their potential changes across childhood and adolescence [18-20]. Similarly, alcohol use behaviours are mainly measured during adolescence and early adulthood, the years during which drinking is typically initiated, escalates [21], and is more influenced by contextual factors (e.g. parenting and peers' drinking behaviours) $[22,23]$. In contrast, drinking in midadulthood stabilizes and might be less contextually influenced [24-26]. How associations between externalising and internalising problems and drinking behaviours vary across sex and historical period is also under-explored, though it is well-established that the prevalence of externalising and internalising problems and alcohol use behaviours differs between males and females [27-30] and fluctuates over historical periods [31]. Moreover, few studies examine the role of externalising and internalising problems simultaneously, which may bias each other's relationship with alcohol outcomes [6], considering their high comorbidity across childhood and adolescence [32].

The present study extends the current literature by investigating the association of early life externalising and internalising problems with problematic drinking in mid-adulthood, and whether these associations are modified by age, sex and cohort using two successive nationally representative longitudinal British birth cohorts.

\section{Methods}

\section{Sample}

We used data from two British birth cohorts born 12 years apart in England, Scotland, and Wales: the 1958 National Child Development Study (NCDS58) and the 1970 British Birth Cohort (BCS70). NCDS58 recruited 17,633 babies born in one week in March 1958 with 10 waves of data collected through 2013. BCS70 recruited 17,568 babies born in one week in April 1970 with 9 waves of data through 2016. Details about both cohorts are available elsewhere [33, 34].

\section{Measures}

Tools used to assess externalising and internalising problems, alcohol outcomes and potential confounding factors varied across waves and cohorts. To explore the potential cohort effect in the associations between externalising and internalising problems and problematic drinking, variables that were consistently collected across cohorts were retained and harmonised for analysis.

\section{Early life mental health problems}

Externalising and internalising problems were measured with the parent rated Rutter Behaviour Questionnaire [35]. In NCDS58, they were assessed using 14 items at ages 7 and 11 , and 18 items at age 16 , while the 19 -item version was collected at ages 5, 10, 16 in BCS70. Exploratory factor analysis was carried out to establish items which represent externalising and internalising problems (see ESM Tables 1, 2). Four items (fights, disobedient, destructive, and irritable) were used to assess externalising problems, and four items (being worried, solitary, fearful and miserable) for internalising problems.

\section{Measures of problematic drinking}

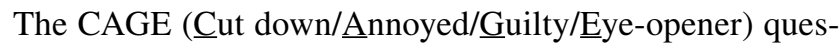
tionnaire is a four-item self-report screening instrument for detecting alcohol problems [36]. The CAGE was collected at age 33 in NCDS58 and age 34 in BCS70. A score of 2 or more indicates a propensity for AUD [36]. The AUDIT (Alcohol Use Disorder Identification Test) was developed by the World Health Organization (WHO) to identify those with hazardous and harmful patterns of alcohol consumption [37]. The full AUDIT with 10 questions assessing past-year drinking behaviours was collected at ages 44/45 in NCDS58, but only the primary-care AUDIT (AUDIT-PC) with 5 questions was collected at age 46 in BCS70 and thus was used in the current study (see ESM Table 3). For simplicity, we use age 45 to refer to this timepoint throughout the manuscript. A score of 5 or over indicated problematic drinking [38].

\section{Potential confounders}

Based on previous literature [39, 40], a series of potential confounding factors that were comparable across cohorts were selected and included in our models. More information regarding how the variables were derived can be found in ESM Table 4. Confounding factors include birth weight (grams), gestational age (days), maternal smoking during pregnancy, maternal age at birth (years), ever being breastfed, whether the mother stayed at school after minimum school leaving age, whether the father stayed at school after minimum school leaving age, parents' marital status (birth, ages 5/7, 10/11 and 16), father's social class (birth, ages $5 / 7,10 / 11$ and 16), whether parents read to child weekly (age 5/7), whether housing tenure was owned (age 5/7), household amenities (bathroom, indoor toilet, kitchen and 
hot water) (ages $5 / 7$ and 16), person room ratio in the house (ages 5/7, 10/11 and 16), whether mother worked before child went to school (age 5/7), whether the mother was separated from the child for more than one month (age 5/7), parents' interest in child's education (age 10/11), how many times family had moved (age 5/7), body mass index (ages 10/11 and 16), cognitive ability (age 5/7 and 10/11), physical health conditions (ages 5/7 and 10/11), and bedwetting (age 5/7).

\section{Statistical analysis}

Item Response Theory models were applied to derive continuous latent scores at each wave in childhood and adolescence, allowing the externalising and internalising scores to be correlated [41] (see ESM Table 5). High latent scores indicate higher externalising and internalising problems, respectively.

The conceptual framework that guided our analysis is displayed in Fig. 1. Externalising and internalising problems were assumed to be associated with problematic drinking directly and indirectly through later mental health status. At the same time, time-invariant and time-varying confounding factors may bias the associations. As confounding factors such as genes or family history of alcohol problems were not collected in the cohorts, the associations after adjusting for observed confounders may still be biased by residual/ unmeasured confounding. Therefore, based on the findings that high co-occurrence between externalising and internalising problems is mainly due to a common cause [32, 42-45], we argue that externalising and internalising problems at the same age should be adjusted simultaneously to reduce bias due to unmeasured confounding. For example, by adjusting externalising problems at age $5 / 7$, the spurious association between internalising problems at age 5/7 and problematic drinking due to unmeasured common causes of externalising and internalising problems was blocked [46]. Similarly, the use of lags at ages $5 / 7$ and $10 / 11$ has the potential to reduce unmeasured confounding in the associations between externalising and internalising problems at ages 10/11 and 16 and problematic drinking in mid-adulthood, respectively.

Both cohorts are representative samples of births in Great Britain in 1958 and 1970. The target population for our analyses was cohort members who were still alive when the outcomes were assessed. Thus, the analytic sample size in NCDS58 is $16,600($ male $=8511$, female $=8089)$ at age 33 , and $16,336($ male $=8349$, female $=7987)$ at age $44 / 45$. In BCS70, it is 16,655 (male $=8601$, female $=8054$ ) at age 34 , and 16,593 $($ male $=8586$, female $=8007)$ at age 46 . Due to attrition over more than 40 years (ESM Table 6), which is known to erode sample representativeness if left unchecked, multiple imputation (MI) was implemented. One hundred fifty imputed datasets were generated using chained equations using a two-stage calculation [47-49], and distributions of complete and imputed variables were

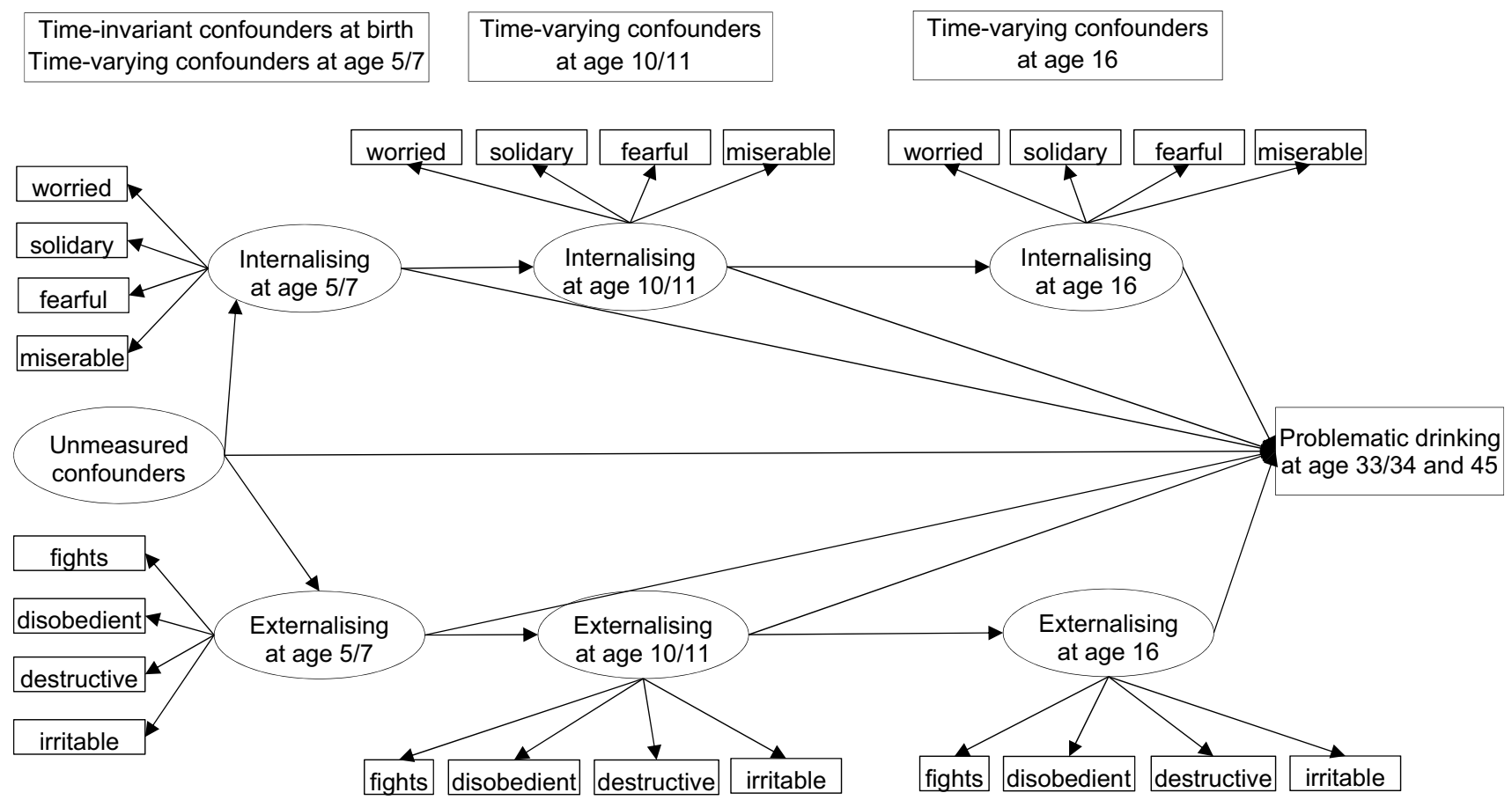

Fig. 1 Conceptual framework. *For clarity, arrows from confounders to externalising/internalising problems at each age and problematic drinking were left out 
checked [50]. Further details on the implementation of MI procedure can be found in ESM Text 1.

The analysis proceeded in two stages. In the first stage, lagged logistic regression was carried out by adding externalising scores, internalising scores and corresponding confounders chronologically to explore the direction of the association and the potential critical period of externalising and internalising problems. For example, externalising and internalising scores at age 5/7 and confounders measured at birth and age 5/7 were first included in Model 1, and then externalising and internalising scores and time-varying confounders at age 10/11 were further added in Model 2. Last, externalising and internalising scores and confounders at age 16 were added in Model 3. To investigate potential critical periods of experiencing externalising and internalising problems with respect to their associations with later problematic drinking, post hoc comparisons were conducted. For instance, comparisons were made to see whether the coefficient of externalising scores at age 5/7 in Model 1, at age 10/11 in Model 2 and at age 16 in Model 3 were equivalent to each other. Potential increases in Type I error, due to multiple comparisons, were corrected using Bonferroni corrections at a threshold of $0.017(0.05 / 3)$ for the $P$ value. In the second stage, interactions of externalising and internalising problems at each age with sex and cohort were investigated. This was achieved by adding interaction terms into the previous models. The above models are displayed in notation form in ESM Text 2.

A series of sensitivity analyses were carried out to assess the robustness of our results from various perspectives. The rationale of each analysis is articulated in ESM Text 3 , and results are presented and discussed where appropriate.

\section{Results}

As shown in Table 1, at ages 5/7 and 10 , level of externalising problems was higher in males compared to that in females, and level of internalising problems was similar across sex. However, at age 16, levels of externalising and internalising problems tended to be higher in females than those in males. Prevalence of problematic drinking, though assessed using different scales, was about 2 times higher in males compared to that in females across cohorts at ages $33 / 34$ and 45.

Externalising and internalising problems at each age in childhood and adolescence were associated in opposite directions with problematic drinking, and these associations persisted across mid-adulthood (see Table 2). Externalising problems acted as a risk factor for problematic drinking in mid-adulthood, while internalising problems served as a protective factor. The size of the $E$ value ranged from 1.20 to 1.29 , indicating that an unmeasured confounding factor would still need to be associated with externalising or internalising problems and problematic drinking at a risk ratio of $1.20-1.29$ to nullify the observed association to 1 . The strength needed to render the confidence interval to include 1 was smaller (1.08-1.22).

Post hoc comparisons indicate that the strength of the associations (absolute value of the coefficients) with problematic drinking did not differ between externalising and internalising problems, and that the strength of the associations between externalising or internalising problems measured at age $5 / 7$, age $10 / 11$ and age 16 and problematic drinking in adulthood did not differ by age.

Interactions of externalising and internalising problems with sex predicting the probability of problematic drinking were mainly detected at age 16 . These are plotted in Fig. 2 with more detail in ESM Table 8. We observed an

Table 1 Descriptive statistics for externalising and internalising score and problematic drinking across sex and cohorts

\begin{tabular}{|c|c|c|c|c|c|c|c|c|}
\hline & \multicolumn{4}{|c|}{ NCDS58 } & \multicolumn{4}{|c|}{ BCS70 } \\
\hline & \multicolumn{2}{|l|}{ Male } & \multicolumn{2}{|c|}{ Female } & \multicolumn{2}{|l|}{ Male } & \multicolumn{2}{|c|}{ Female } \\
\hline & \multicolumn{8}{|c|}{ Mean \pm SD } \\
\hline Externalising score at age $5 / 7$ & 7319 & $0.16 \pm 1.04$ & 6933 & $-0.17 \pm 1.05$ & 6698 & $0.18 \pm 1.18$ & 6232 & $-0.20 \pm 1.11$ \\
\hline Internalising score at age $5 / 7$ & 7319 & $-0.00 \pm 1.26$ & 6933 & $+0.00 \pm 1.28$ & 6698 & $0.03 \pm 1.10$ & 6232 & $-0.03 \pm 1.14$ \\
\hline Externalising score at age $10 / 11$ & 6821 & $0.17 \pm 1.11$ & 6480 & $-0.18 \pm 1.08$ & 6750 & $0.18 \pm 1.45$ & 6373 & $-0.19 \pm 1.28$ \\
\hline Internalising score at age $10 / 11$ & 6821 & $0.01 \pm 1.34$ & 6480 & $-0.02 \pm 1.37$ & 6750 & $0.03 \pm 1.51$ & 6373 & $-0.04 \pm 1.56$ \\
\hline Externalising score at age 16 & 5692 & $-0.09 \pm 1.58$ & 5432 & $0.10 \pm 1.60$ & 4123 & $-0.07 \pm 1.85$ & 4320 & $0.07 \pm 1.82$ \\
\hline \multirow[t]{2}{*}{ Internalising score at age 16} & 5692 & $-0.14 \pm 1.15$ & 5432 & $0.15 \pm 1.26$ & 4123 & $-0.14 \pm 1.38$ & 4320 & $0.13 \pm 1.51$ \\
\hline & \multicolumn{8}{|c|}{$N(\%)$} \\
\hline CAGE at age $33 / 34$ & 5359 & $924(17.24 \%)$ & 5543 & $437(7.88 \%)$ & 4414 & $1031(23.36 \%)$ & 4779 & $650(13.60 \%)$ \\
\hline AUDIT-PC at age 45 & 4439 & $1933(43.55 \%)$ & 4514 & $901(19.96 \%)$ & 3973 & $1217(30.63 \%)$ & 4292 & $719(16.75 \%)$ \\
\hline
\end{tabular}


Table 2 Associations between externalising and internalising problems and problematic drinking at age $33 / 34$ and age 45 in two British birth cohorts

\begin{tabular}{|c|c|c|c|c|c|c|}
\hline & Model 1 & $E$ value $^{\mathrm{a}}$ & Model 2 & $E$ value & Model 3 & $E$ value \\
\hline \multicolumn{7}{|c|}{ PD (CAGE) at age $33 / 34$} \\
\hline EXT at age $5 / 7$ & $1.10(1.05,1.15)^{* * *}$ & $1.28(1.18)$ & $1.07(1.02,1.12)^{* *}$ & NA & $1.05(1.00,1.10)$ & NA \\
\hline INT at age $5 / 7$ & $0.96(0.92,1.00)$ & $1.17(1.00)$ & $0.97(0.93,1.02)$ & NA & $0.98(0.93,1.02)$ & NA \\
\hline EXT at age $10 / 11$ & & & $1.09(1.04,1.15)^{* * *}$ & $1.26(1.16)$ & $1.05(1.00,1.11)^{*}$ & NA \\
\hline INT at age $10 / 11$ & & & $0.95(0.92,0.99)^{*}$ & $1.19(1.08)$ & $0.97(0.93,1.01)$ & NA \\
\hline EXT at age 16 & & & & & $1.11(1.06,1.16)^{* * *}$ & $1.29(1.20)$ \\
\hline INT at age 16 & & & & & $0.93(0.87,0.99)^{*}$ & $1.23(1.08)$ \\
\hline$N$ & 33,255 & & 33,255 & & 33,255 & \\
\hline \multicolumn{7}{|c|}{ PD (AUDIT-PC) at age 45} \\
\hline EXT at age $5 / 7$ & $1.06(1.03,1.10)^{* * *}$ & $1.20(1.14)$ & $1.05(1.01,1.09)^{*}$ & NA & $1.03(0.99,1.08)$ & NA \\
\hline INT at age $5 / 7$ & $0.94(0.91,0.98)^{* * *}$ & $1.21(1.11)$ & $0.96(0.93,1.00)^{*}$ & NA & $0.97(0.94,1.01)$ & NA \\
\hline EXT at age $10 / 11$ & & & $1.07(1.03,1.11)^{* *}$ & $1.22(1.14)$ & $1.03(0.99,1.08)$ & NA \\
\hline INT at age $10 / 11$ & & & $0.94(0.91,0.97)^{* * *}$ & $1.21(1.14)$ & $0.96(0.93,0.99)^{*}$ & NA \\
\hline EXT at age 16 & & & & & $1.11(1.07,1.15)^{* * *}$ & $1.29(1.22)$ \\
\hline INT at age 16 & & & & & $0.90(0.86,0.94)^{* * *}$ & $1.29(1.21)$ \\
\hline$N$ & 32,929 & & 32,929 & & 32,929 & \\
\hline
\end{tabular}

Confounding factors were added chronologically as described in the method section. Logistic regression was run, and thus results are reported as OR $(95 \%)$. Scale of latent score for externalising and internalising problems was constrained by fixing the factor loading of "worried" and "irritable" to 1 to ensure the comparability across ages and cohorts; coefficients of standardised latent score can be found in ESM Table 7

EXT externalising problems, INT internalising problems, $P D$ problematic drinking

$* p<0.05, * * p<0.01, * * * p<0.001$

${ }^{a} \mathrm{NA}$ refers to not applicable. The value outside the bracket is $E$ value for the point estimate, and the value in the bracket is $E$ value for the limit of the confidence interval closest to the null (the strength needed to move the confidence interval to include 1)

interaction between externalising problems at age 16 and sex predicting problematic drinking at age $33 / 34(p=0.028)$, with the association between externalising problems and problematic drinking at age 33/34 being observed only in males. An interaction between internalising problems and sex was detected at both age $33 / 34(p<0.001)$ and age 45 $(p=0.026)$, with the association being stronger in males.

We did not observe interactions between externalising or internalising problems and cohort regarding their associations with problematic drinking at any age (ESM Table 8).

\section{Discussion}

By analysing data from two population-based prospective British birth cohorts born 12 years apart, we found that externalising problems across childhood and adolescence acted as a risk factor for problematic drinking in adulthood. In contrast, a negative association between internalising problems and problematic drinking was observed, which indicates that those experiencing internalising symptoms in childhood or adolescence were less likely to exhibit problematic drinking in mid-adulthood. We did not detect a critical period of experiencing externalising and internalising problems between early childhood and mid-adolescence regarding their associations with problematic drinking. Strength of the associations did not differ significantly across cohorts but were stronger in males.

Existing evidence is quite inconsistent regarding the association between early life internalising problems and alcohol use behaviours in adulthood [51, 52]. This may be due to methodological differences, since studies that found positive associations either measured alcohol outcomes in adolescence or early adulthood (from age 16 to age 25) or were conducted in American or Australian settings, and crucially did not adjust for externalising problems [53, 54]. By comparison, studies reporting negative associations either measured alcohol outcomes at mid/late adulthood (age 26 onwards) and adjusted for externalising problems [10, 12, 55] or were conducted in the UK $[10,12]$. Thus, the life course stage at which alcohol behaviour was measured, whether externalising problems were adjusted for, as well as the cultural context might explain part of the divergence among studies.

The association between early life internalising problems and later alcohol use behaviours may vary across the life course, as determinants and patterns of drinking typically change with development. Adolescence is a period of dramatic changes physically, psychologically and socially; drinking in this period is strongly socially-driven, greatly 

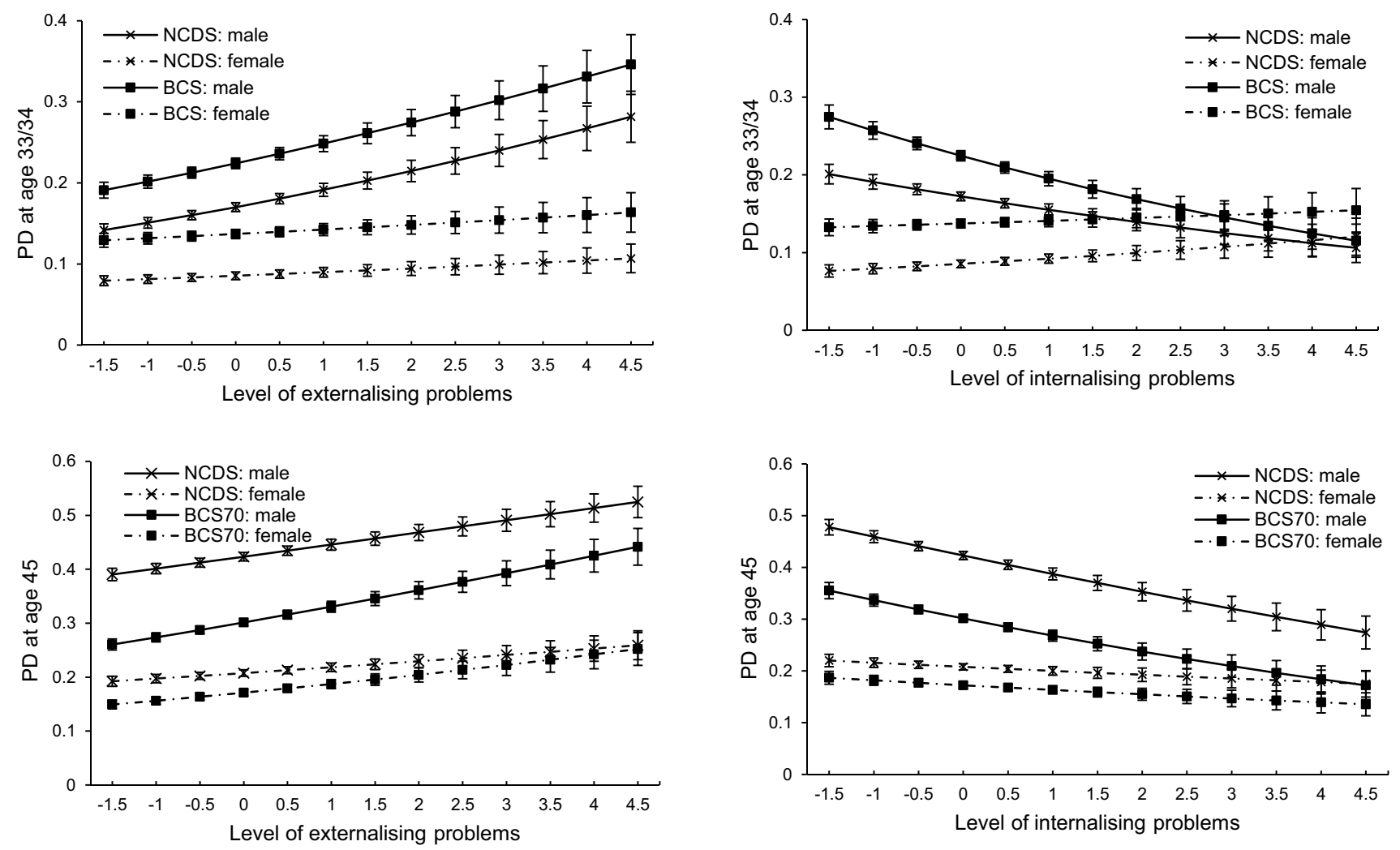

Fig. 2 Probability of problematic drinking (PD) at different level of externalising and internalising problems at age 16

affected by social norms, peer influences and parents' monitoring $[22,56]$. For many, early adulthood is characterised by a series of role transitions that coincide with normative but not universal reductions in alcohol consumption [57, 58]. In mid-adulthood, lifestyle behaviours often have solidified into more regular patterns [26], and may reflect longer-term origins back in childhood and adolescence [59-61]. Here, adults who had experienced more internalising problems early in life were less likely to report problematic drinking in mid/late adulthood.

Furthermore, the association between early life internalising problems and alcohol use behaviours in adulthood may vary across populations. The proposed internalising pathway to alcohol use/disorder suggests that people with internalising problems use alcohol to self-medicate or gain acceptance by peers [5]. However, this may not be the primary mechanism of action in the British context, where alcohol has been used as a way of socializing at least since its popularity increased after World War II [62]. Children or adolescent with internalising problems (measured via items capturing solitary, fearful of new things, worried about many things and miserable/tearful) may experience reduced exposure to alcohol because they spent less time at pubs, bars and clubs. This aligns with the hypothesis that internalising tendencies towards social withdrawal and fear of negative consequences may decrease the risk of problematic drinking through reducing one's exposure to alcohol use [63, 64]. Our results indicate that the protective effect of early life internalising problems persists into mid-adulthood in the UK context, and are consistent with another UK-based population study [12].

Our results support the possibility that not adjusting for externalising problems could introduce residual confounding in the association between internalising problems and alcohol outcomes. The observed opposite direction of the associations of externalising and internalising problems with alcohol outcomes has also been found in previous studies where externalising and internalising problems were adjusted for simultaneously [10, 13, 65-68]. In our study, we observed systematic attenuation of the association when externalising and internalising problems were added into the model separately (see ESM Tables 9, 10 and Table 2). To illustrate with a Directed Acyclic Graph in Fig. 3 [46, 69], when externalising problems were not adjusted, the association between internalising and problematic drinking was a combination of two paths. One represented the path of interest (internalising problems $\rightarrow$ problematic drinking) and the other carried a spurious association (internalising problems $\leftarrow$ unmeasured confounders $\rightarrow$ externalising problems $\rightarrow$ problematic drinking) which was positive. Thus, when externalising problems were not adjusted, the true association of interest 


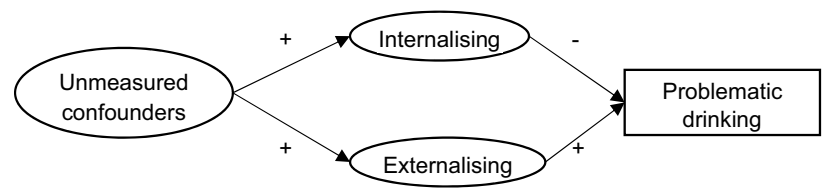

Fig. 3 DAG illustration of the suppressing effect between externalising and internalising problems

which was negative could be attenuated, cancelled out or even reversed depending on the strength of the association between externalising problems and alcohol outcomes in the population. When a general psychological factor that captured the common variance of externalising and internalising problems was employed as an exposure, we found that the association between the psychopathological factor and problematic drinking was the average of the association of externalising problems with problematic drinking and that of internalising problems with problematic drinking (ESM Table 11). In addition, we did not observe large standard errors or variance inflation factors [70]. Therefore, the observed opposite associations between externalising and internalising problems with problematic drinking should be seen as evidence of a suppressing effect rather than a consequence of multicollinearity.

Results from post hoc comparisons did not identify any critical periods in childhood or adolescence when experiencing mental health problems showed a stronger or weaker association with problematic drinking in adulthood. Few studies have had sufficient longitudinal data to explore the developmental timing of externalising or internalising behaviours and their potential impact on alcohol use behaviours in mid-adulthood. Individuals with externalising problems may actively self-select into environments and peer settings where alcohol use is common, consistent with their dispositions, and they may be reinforced reciprocally by these environments [71]. Person-based analysis that derived trajectories of externalising problems, showed that externalising problems in late adolescence may be a key dimension: compared to those with consistently low level of externalising problems, those with either early-onset-persistent or adolescentonset externalising problems had worse outcomes, while childhood-limited externalising problems were not associated with later alcohol use behaviours [72-77]. In this context, the detection of a critical period may depend on the proportion of individuals with childhood-limited and adolescent-onset externalising problems in the population. By adjusting latent scores of previous externalising and internalising problems in the model, our results avoid the influence of the constitution of heterogeneous trajectories in the population and indicate that there were no critical periods of mental health problems between childhood and adolescence regarding the strength of their relationship with problematic drinking in the British population. However, this conflicting implication between results of our study and those of person-based analysis warrants more exploration, and future research would offer new insights if both approaches could be carried out within one study.

Another finding worth our attention is how the associations between externalising and internalising problems and problematic drinking differed significantly across sex but not cohorts. Born 12 years apart, participants from NCDS58 and BCS70 were raised during a time of shifting social environments towards alcohol $[78,79]$. Though the prevalence of problematic drinking at different ages differed significantly across cohorts, the strength of the associations between externalising and internalising problems and problematic drinking generally did not differ, which is consistent with previous findings [31]. At least for these two generations born in 1958 and 1970, the observed associations between early life mental health and later problematic drinking reflect general developmental processes, and there is no evidence that their association reflects historical changes in patterns and culture of alcohol use [31]. However, we did see suggestive evidence for stronger links between externalising problems in childhood and adolescence and problematic drinking in midlife in the later-born BCS70 cohort than those in the NCDS58 cohort. That is, the interaction terms between externalising scores and cohort (NCDS58 as reference) with problematic drinking at age 45 tended to be positive (ESM Table 8), and the curve between the externalising score and the probability of problematic drinking at age 45 was steeper in BCS70 compared to that in NCDS58 (Fig. 2). These differences, if sustained in the long run in more recently born cohorts, will lead to a stronger association between externalising problems and problematic drinking. Modification by sex in the associations of externalising and internalising problems with problematic drinking was found with the associations being stronger in males, especially for internalising problems. Traditionally and even today in the UK, males consumed alcohol more frequently in pubs $[62,80]$. As earlier life internalising problems in our study were assessed using indicators such as being "fearful" and "solitary", this may help explain the stronger association among males. The majority of prior studies examining interactions between mental health problems and sex predicting alcohol use in adulthood have found none [7, 8, $15,73,81-87]$, or, have observed inconsistent results [55, 88-90]. Noticeably, for generations born around or after 1980s in the UK, women have been shown to consume alcohol similarly to their male counterparts [91]. Thus, we could not rule out the possibility that variation of the 
association across sex reported here would disappear for recent generations in the UK.

\section{Policy implications}

If causal, our findings have implications for public policy. First, externalising problems instead of internalising problems might be a better target for early life intervention to alleviate alcohol burden in adulthood in the UK context. Though the high co-occurrence between externalising and internalising problems is well-established [92, 93], most existing intervention programmes shown to be effective target them separately [94]. Second, strategies of promoting sensible drinking should be incorporated when targeting internalising problems to tackle their detrimental effects on other aspects of life (e.g. adult mental health, psychosocial outcomes) $[95,96]$. One should be vigilant of the potential subsequent alcohol burden after the intervention. Third, more evidence is warranted to examine whether the externalising pathway is stronger in males in generations born after 1970 and to explain the discrepancies regarding possible critical periods of mental health from both person-based and variable-based perspectives. Such evidence will have further implications on who (males versus females) and when (at which age) should be targeted in more recent generations to alleviate their potential alcohol burden.

\section{Strengths and limitations}

Strengths of our study include the availability of two well-characterised prospective national birth cohorts with repeated measures of mental health that span childhood and adolescence and measures of problematic drinking in early adulthood and midlife. This adds to the scarce evidence on how far into adulthood the pathway from early mental health to alcohol use persists. Furthermore, considering the high rate of co-occurrence between externalising and internalising problems in childhood and adolescence [32, 42, 97], the association of externalising and internalising problems with problematic drinking was investigated both simultaneously and separately to investigate their potential suppressing effect on each other, which has been ignored in most previous studies. Various forms of sensitivity analyses supported the robustness of our findings. Our analytic approach aimed to reduce bias from, arguably, its three major sources in observational studies: measurement error (ESM Text4 and ESM Tables 12-17), residual confounding (Table2 and ESM Table 9, 10, 18), and missing data related selection bias (ESM Table 19) [98].

Several limitations should also be considered when interpreting our findings. As in any other longitudinal survey, selective attrition is unavoidable. In this instance, about $60 \%$ of the original sample was retained by age 46 in both cohorts. By making use of the abundant information collected in both longitudinal studies [99], we imputed 150 datasets and carried out sensitivity analysis with only cases with complete outcome data. Though results showed that our results were quite robust to attrition, selection bias cannot be ruled out. Furthermore, our measurement may not reflect the whole range of externalising and internalising problems. Only four items were retained to assess externalising and internalising problems. Though the latent scores derived utilising four items are highly correlated with the latent scores derived utilising all relevant items in the Rutter scales $(r>0.95$ for NCDS58, $r>0.92$ for BCS70), externalising and internalising problems in our study should be interpreted with caution, especially when comparing the results with other studies. Third, the short version of AUDIT used in our study increases the rate of false positives in detecting problematic drinking (Table 1 and ESM Tables 14, 15) and biases our results towards the null. This was observed in sensitivity analysis when the full-AUDIT scale in NCDS58 was utilised (ESM Table 16). Fourth, despite the relatively rich set of confounders that were included in the models, other potential confounders (e.g. family history of alcoholism, parenting strategy, peers' drinking behaviours) were not adjusted in our study due to their unavailability. Adjusting highly correlated externalising and internalising problems simultaneously and their lags has the potential of blocking these potential confounders at least partially (ESM Tables 9, 10, 18). In addition, the $E$ value, which evaluates the minimum strength - on the risk ratio scale - that an unmeasured confounder would need to have with both exposure and outcome to fully explain away the observed association (conditional on the measured confounding factors), was calculated [100]. However, the size of the $E$ value in our study (Table 2) could be interpreted from two perspectives. On one hand, the size of the $E$ value (1.20-1.29) indicates that the association of the unmeasured confounder with problematic drinking, conditional on all the covariates included in the model, would need to be stronger than the observed associations of externalising problems with problematic drinking (1.06-1.11) in our study. Thus, it could be argued that the observed associations were less likely to be fully nullified by unmeasured confounding factors, as the externalising pathway is, up to now, shown to be the most robust pathway [101]. On the other hand, the size of the E-value could also be seen to indicate that the observed associations were still susceptible to unmeasured confounding factors, including genetics [102, 103], parental psychopathology and substance use and peers' drinking behaviours [104]. However, the lack of studies examining the strength of those potential confounders with problematic drinking into mid-adulthood while taking externalising and internalising problems into account constrains further speculations. Future studies would offer more insights if they 
could examine whether genetics and familial and social risk factors act as potential confounding factors for the pathway from externalising problems to problematic drinking or act as upstream factors which are linked to problematic drinking only through externalising problems.

\section{Conclusion}

By utilising two British birth cohorts, we found that externalising problems in childhood and adolescence were positively associated with problematic drinking across mid-adulthood while internalising problems were negatively associated with problematic drinking, and the results were robust in a series of sensitivity analyses. We also found no evidence for a particular critical period for experiencing externalising and internalising problems in childhood or adolescence that was uniquely important as predictors of problematic drinking in mid-adulthood. The stability of these associations across two UK cohorts born 12 years apart indicates the developmental nature of the association between externalising and internalising problems and problematic drinking. More evidence is needed to examine whether the detected sex differences in the associations persist for more recent generations. Our study provides new insights on links of externalising and internalising problems with alcohol use in the UK. If causal, our findings could inform design of early life interventions to reduce alcohol burden in adulthood.

Supplementary Information The online version contains supplementary material available at https://doi.org/10.1007/s00127-021-02063-3.

Author contributions Conceptualization: KN, GBP, PP, JM; Methodology: KN, GBP; Formal analysis and investigation: KN; Writingoriginal draft preparation: $\mathrm{KN}$; Writing — review and editing: KN, GBP, PP, JM; Funding acquisition: KN; Resources: KN; Supervision: GBP, $\mathrm{PP}, \mathrm{JM}$.

Funding Preparation of this manuscript was part of a $\mathrm{PhD}$ project funded by the Economic Social Research Council (ESRC) (ESRC+3 $\mathrm{PhD}$ ) and a UCL Overseas Research Scholarship.

Availability of data and materials Available upon request.

Code availability Available upon request.

\section{Declarations}

Conflict of interest The authors declare that they have no conflicts of interest.

Ethical standards The manuscript does not contain clinical studies or patient data.

Open Access This article is licensed under a Creative Commons Attribution 4.0 International License, which permits use, sharing, adaptation, distribution and reproduction in any medium or format, as long as you give appropriate credit to the original author(s) and the source, provide a link to the Creative Commons licence, and indicate if changes were made. The images or other third party material in this article are included in the article's Creative Commons licence, unless indicated otherwise in a credit line to the material. If material is not included in the article's Creative Commons licence and your intended use is not permitted by statutory regulation or exceeds the permitted use, you will need to obtain permission directly from the copyright holder. To view a copy of this licence, visit http://creativecommons. org/licenses/by/4.0/.

\section{References}

1. Degenhardt L, Charlson F, Ferrari A, Santomauro D, Erskine H, Mantilla-Herrara A et al (2018) The global burden of disease attributable to alcohol and drug use in 195 countries and territories, 1990-2016: a systematic analysis for the Global Burden of Disease Study 2016. Lancet Psychiatry 5:987-1012. https://doi.org/10.1016/S2215-0366(18)30337-7

2. Hicks BM, Zucker RA (2014) Alcoholism: a life span perspective on etiology and course. In: Lewis M, Rudolph KD (eds) Handb. dev. psychopathol. Springer US, Boston, pp 583-599. https://doi.org/10.1007/978-1-4614-9608-3_29

3. Zucker RA (2015) Alcohol use and the alcohol use disorders: a developmental-biopsychosocial systems formulation covering the life course. In: Cicchetti D, Cohen DJ (eds) Dev. psychopathol. Wiley, pp 620-656. https://doi.org/10.1002/97804 70939406.ch17

4. Zucker RA, Hicks BM, Heitzeg MM (2016) Alcohol use and the alcohol use disorders over the life course: a cross-level developmental review. Dev. psychopathol. American Cancer Society, pp 1-40. https://doi.org/10.1002/9781119125556. devpsy318

5. Hussong AM, Jones DJ, Stein GL, Baucom DH, Boeding S (2011) An internalizing pathway to alcohol use and disorder. Psychol Addict Behav 25:390-404

6. Ning K, Gondek D, Patalay P, Ploubidis GB (2020) The association between early life mental health and alcohol use behaviours in adulthood: a systematic review. PLoS ONE 15:e0228667. https://doi.org/10.1371/journal.pone.0228667

7. Edwards AC, Gardner CO, Hickman M, Kendler KS (2016) A prospective longitudinal model predicting early adult alcohol problems: evidence for a robust externalizing pathway. Psychol Med 46:957-968

8. Pesola F, Shelton KH, Heron J, Munafò M, Hickman M, Van Den Bree MBM (2015) The developmental relationship between depressive symptoms in adolescence and harmful drinking in emerging adulthood: the role of peers and parents. J Youth Adolesc 44:1752-1766

9. Virtanen P, Nummi T, Lintonen T, Westerlund H, Hägglöf B, Hammarström A (2015) Mental health in adolescence as determinant of alcohol consumption trajectories in the Northern Swedish Cohort. Int J Public Health 60:335-342. https://doi. org/10.1007/s00038-015-0651-5

10. Maggs JL, Patrick ME, Feinstein L (2008) Childhood and adolescent predictors of alcohol use and problems in adolescence and adulthood in the National Child Development Study. Addiction 103:7-22

11. Stice E, Myers MG, Brown SA (1998) A longitudinal grouping analysis of adolescent substance use escalation and de-escalation. Psychol Addict Behav 12:14-27 
12. von Stumm S, Deary IJ, Kivimäki M, Jokela M, Clark H, Batty GD (2011) Childhood behavior problems and health at midlife: 35-year follow-up of a Scottish birth cohort. J Child Psychol Psychiatry 52:992-1001. https://doi.org/10.1111/j.1469-7610. 2011.02373.x

13. Niemela S, Sourander A, Poikolainen K, Helenius H, Sillanmaki L, Parkkola K et al (2006) Childhood predictors of drunkenness in late adolescence among males: a 10-year population-based follow-up study. Addiction 101:512-521. https://doi.org/10. 1111/j.1360-0443.2006.01381.x

14. Boyle Michael H, Offord David R, Racine Yvonne A, Szatmari P, Fleming Jan E, Links PS (1992) Predicting substance use in late adolescence: results from the Ontario Child Health Study follow-up. Am J Psychiatry 149:761-767

15. Jun H-J, Sacco P, Bright CL, Camlin EAS (2015) Relations among internalizing and externalizing symptoms and drinking frequency during adolescence. Subst Use Misuse 50:1814-1825

16. Hicks BM, Iacono WG, McGue M (2010) Consequences of an adolescent onset and persistent course of alcohol dependence in men: adolescent risk factors and adult outcomes. Alcohol Clin Exp Res 34:819-833. https://doi.org/10.1111/j.1530-0277.2010. 01154.x

17. Meier MH, Caspi A, Houts R, Slutske WS, Harrington H, Jackson KM et al (2013) Prospective developmental subtypes of alcohol dependence from age 18 to 32 years: implications for nosology, etiology, and intervention. Dev Psychopathol 25:785-800. https://doi.org/10.1017/S0954579413000175

18. Petersen IT, Bates JE, Dodge KA, Lansford JE, Pettit GS (2015) Describing and predicting developmental profiles of externalizing problems from childhood to adulthood. Dev Psychopathol 27:791-818. https://doi.org/10.1017/S0954579414000789

19. Shanahan L, Calkins SD, Keane SP, Kelleher R, Suffness R (2014) Trajectories of internalizing symptoms across childhood: the roles of biological self-regulation and maternal psychopathology. Dev Psychopathol 26:1353-1368. https://doi.org/10.1017/ S0954579414001072

20. Melchior M, Touchette E, Prokofyeva E, Chollet A, Fombonne E, Elidemir G et al (2014) Negative events in childhood predict trajectories of internalizing symptoms up to young adulthood: an 18-year longitudinal study. PLoS ONE 9:e114526. https:// doi.org/10.1371/journal.pone.0114526

21. Schulenberg JE, Maslowsky J, Patrick ME, Martz M (2015) Substance use in the context of adolescent development. Oxf Handb Adolesc Subst Abuse. https://doi.org/10.1093/oxfordhb/97801 99735662.013.38

22. Deutsch AR, Wood PK, Slutske WS (2017) Developmental etiologies of alcohol use and their relations to parent and peer influences over adolescence and young adulthood: a genetically informed approach. Alcohol Clin Exp Res 41:2151-2162. https:// doi.org/10.1111/acer.13506

23. Dick DM (2016) The genetics of addiction: where do we go from here? J Stud Alcohol Drugs 77:673-675. https://doi.org/ 10.15288/jsad.2016.77.673

24. Emslie C, Hunt K, Lyons A (2012) Older and wiser? Men's and women's accounts of drinking in early mid-life. Sociol Health Illn 34:481-496. https://doi.org/10.1111/j.1467-9566.2011. 01424.x

25. Parke H, Michalska M, Russell A, Moss AC, Holdsworth C, Ling $\mathrm{J}$ et al (2018) Understanding drinking among midlife men in the United Kingdom: a systematic review of qualitative studies. Addict Behav Rep 8:85-94. https://doi.org/10.1016/j.abrep. 2018.08.001

26. Britton A, Ben-Shlomo Y, Benzeval M, Kuh D, Bell S (2015) Life course trajectories of alcohol consumption in the United
Kingdom using longitudinal data from nine cohort studies. BMC Med. https://doi.org/10.1186/s12916-015-0273-z

27. Leadbeater BJ, Kuperminc GP, Blatt SJ, Hertzog C (1999) A multivariate model of gender differences in adolescents' internalizing and externalizing problems. Dev Psychol 35:1268-1282. https://doi.org/10.1037/0012-1649.35.5.1268

28. Green H, McGinnity A, Meltzer H, Ford T, Goodman R (2005) Mental health of children and young people in Great Britain, 2004. Office for National Statistics, Newport

29. Hicks BM, Blonigen DM, Kramer MD, Krueger RF, Patrick CJ, Iacono WG et al (2007) Gender differences and developmental change in externalizing disorders from late adolescence to early adulthood: a longitudinal twin study. J Abnorm Psychol 116:433-447. https://doi.org/10.1037/0021-843X.116.3.433

30. Fernandez Castelao C, Kröner-Herwig B (2013) Different trajectories of depressive symptoms in children and adolescents: predictors and differences in girls and boys. J Youth Adolesc 42:1169-1182. https://doi.org/10.1007/s10964-012-9858-4

31. Merline A, Jager J, Schulenberg JE (2008) Adolescent risk factors for adult alcohol use and abuse: stability and change of predictive value across early and middle adulthood. Addiction 103:84-99. https://doi.org/10.1111/j.1360-0443.2008.02178.x

32. Willner CJ, Gatzke-Kopp LM, Bray BC (2016) The dynamics of internalizing and externalizing comorbidity across the early school years. Dev Psychopathol 28:1033-1052. https://doi.org/ 10.1017/S0954579416000687

33. Power C, Elliott J (2006) Cohort profile: 1958 British Birth Cohort (National Child Development Study). Int J Epidemiol 35:34-41. https://doi.org/10.1093/ije/dyi183

34. Elliott J, Shepherd P (2006) Cohort profile: 1970 British Birth Cohort (BCS70). Int J Epidemiol 35:836-843. https://doi.org/10. 1093/ije/dyl174

35. Rutter M, Tizard J, Whitmore K (1970) Education, health and behaviour. Longman

36. Ewing JA (1984) Detecting alcoholism. The CAGE questionnaire. JAMA 252:1905-1907

37. Saunders JB, Aasland OG, Babor TF, de la Fuente JR, Grant M (1993) Development of the alcohol use disorders identification test (AUDIT): who collaborative project on early detection of persons with harmful alcohol consumption-ii. Addict Abingdon Engl 88:791-804

38. Babor TF, Higgins-Biddle JC, Saunders JB, Monteiro MG (2001) The alcohol use disorders identification test: guidelines for use in primary health care. World Health Organization, Geneva

39. Stone AL, Becker LG, Huber AM, Catalano RF (2012) Review of risk and protective factors of substance use and problem use in emerging adulthood. Addict Behav 37:747-775. https://doi. org/10.1016/j.addbeh.2012.02.014

40. Pinto ACS, Luna IT, de Sivla AA, da Pinheiro PNC, Braga VAB, e Souza ÂMA et al (2014) Risk factors associated with mental health issues in adolescents: an integrative review. Rev Esc Enferm USP 48:555-564. https://doi.org/10.1590/S0080-62342 0140000300022

41. de Ayala RJ (2013) The IRT tradition and its applications. Oxf Handb Quant Methods Psychol. https://doi.org/10.1093/oxfor $\mathrm{dhb} / 9780199934874.013 .0008$

42. Cosgrove VE, Rhee SH, Gelhorn HL, Boeldt D, Corley RC, Ehringer MA et al (2011) Structure and etiology of co-occurring internalizing and externalizing disorders in adolescents. J Abnorm Child Psychol 39:109-123. https://doi.org/10.1007/ s10802-010-9444-8

43. Mesman J, Koot HM (2000) Common and specific correlates of preadolescent internalizing and externalizing psychopathology. J Abnorm Psychol 109:428-437. https://doi.org/10.1037//0021843X.109.3.428 
44. van Wijk-Herbrink MF, Bernstein DP, Broers NJ, Roelofs J, Rijkeboer MM, Arntz A (2018) Internalizing and externalizing behaviors share a common predictor: The effects of early maladaptive schemas are mediated by coping responses and schema modes. J Abnorm Child Psychol 46:907-920. https://doi.org/10. 1007/s10802-017-0386-2

45. Symeou M, Georgiou S (2017) Externalizing and internalizing behaviours in adolescence, and the importance of parental behavioural and psychological control practices. J Adolesc 60:104113. https://doi.org/10.1016/j.adolescence.2017.07.007

46. Pearl J, Mackenzie D (2018) The book of why: the new science of cause and effect. Basic Books, Inc.

47. Azur MJ, Stuart EA, Frangakis C, Leaf PJ (2011) Multiple imputation by chained equations: what is it and how does it work? Int J Methods Psychiatr Res 20:40-49. https://doi.org/10.1002/mpr. 329

48. White IR, Royston P, Wood AM (2011) Multiple imputation using chained equations: issues and guidance for practice. Stat Med 30:377-399. https://doi.org/10.1002/sim.4067

49. von Hippel PT (2018) How many imputations do you need? A two-stage calculation using a quadratic rule. Sociol Methods Res. https://doi.org/10.1177/0049124117747303

50. Eddings W, Marchenko YV (2012) Diagnostics for multiple imputation in Stata. Stata J 12:353-367

51. Hussong AM, Ennett ST, Cox MJ, Haroon M (2017) A systematic review of the unique prospective association of negative affect symptoms and adolescent substance use controlling for externalizing symptoms. Psychol Addict Behav 31:137-147. https://doi.org/10.1037/adb0000247

52. Dyer ML, Easey KE, Heron J, Hickman M, Munafò MR (2019) Associations of child and adolescent anxiety with later alcohol use and disorders: a systematic review and meta-analysis of prospective cohort studies. Addiction 114:968-982. https://doi. org/10.1111/add.14575

53. Delfabbro PH, Winefield HR, Winefield AH, Hammarstrom A (2016) Mid-adolescent predictors of adult drinking levels in early adulthood and gender differences: longitudinal analyses based on the south Australian school leavers study. J Addict 2016:1489691-1489691. https://doi.org/10.1155/2016/14896 91

54. Parrish KH, Atherton OE, Quintana A, Conger RD, Robins RW (2016) Reciprocal relations between internalizing symptoms and frequency of alcohol use: findings from a longitudinal study of Mexican-origin youth. Psychol Addict Behav 30:203-208

55. Green KM, Zebrak KA, Robertson JA, Fothergill KE, Ensminger ME (2012) Interrelationship of substance use and psychological distress over the life course among a cohort of urban African Americans. Drug Alcohol Depend 123:239-248

56. Bucholz KK, McCutcheon VV, Agrawal A, Dick DM, Hesselbrock VM, Kramer JR et al (2017) Comparison of parent, peer, psychiatric, and cannabis use influences across stages of offspring alcohol involvement: evidence from the COGA prospective study. Alcohol Clin Exp Res 41:359-368. https://doi. org/10.1111/acer.13293

57. Patrick ME, Rhew IC, Lewis MA, Abdallah DA, Larimer ME, Schulenberg JE et al (2018) Alcohol motivations and behaviors during months young adults experience social role transitions: microtransitions in early adulthood. Psychol Addict Behav 32:895-903. https://doi.org/10.1037/adb0000411

58. Schulenberg JE, Maggs JL (2002) A developmental perspective on alcohol use and heavy drinking during adolescence and the transition to young adulthood. J Stud Alcohol s14:54-70. https:// doi.org/10.15288/jsas.2002.s14.54
59. Tuuli P, Katja K, Anna-Liisa L, Lea P (2008) A developmental approach to alcohol drinking behaviour in adulthood: a follow-up study from age 8 to age 42. Addiction 103:48-68

60. Edwards AC, Kendler KS (2013) Alcohol consumption in men is influenced by qualitatively different genetic factors in adolescence and adulthood. Psychol Med 43:1857-1868. https://doi. org/10.1017/S0033291712002917

61. Bergen SE, Gardner CO, Kendler KS (2007) Age-related changes in heritability of behavioral phenotypes over adolescence and young adulthood: a meta-analysis. Twin Res Hum Genet 10:423433. https://doi.org/10.1375/twin.10.3.423

62. Mass Observation (2011) The Pub and the people: a worktown study. Faber \& Faber

63. Colder CR, Scalco M, Trucco EM, Read JP, Lengua LJ, Wieczorek WF et al (2013) Prospective associations of internalizing and externalizing problems and their co-occurrence with early adolescent substance use. J Abnorm Child Psychol 41:667-677. https://doi.org/10.1007/s10802-012-9701-0

64. Colder CR, Chassin L, Lee MR, Villalta IK (2010) Developmental perspectives: affect and adolescent substance use. Subst abuse emot. American Psychological Association, Washington, DC, pp 109-135. https://doi.org/10.1037/12067-005

65. Foster KT, Hicks BM, Zucker RA (2018) Positive and negative effects of internalizing on alcohol use problems from childhood to young adulthood: the mediating and suppressing role of externalizing. J Abnorm Psychol 127:394-403. https://doi.org/ 10.1037/abn0000337

66. Pardini D, White HR, Stouthamer-Loeber M (2007) Early adolescent psychopathology as a predictor of alcohol use disorders by young adulthood. Drug Alcohol Depend 88:S38-49

67. Pulkkinen L, Pitkänen T (1994) A prospective study of the precursors to problem drinking in young adulthood. J Stud Alcohol 55:578-587. https://doi.org/10.15288/jsa.1994.55.578

68. Heradstveit O, Skogen JC, Bøe T, Hetland J, Pedersen MU, Hysing M (2018) Prospective associations between childhood externalising and internalising problems and adolescent alcohol and drug use: the Bergen Child Study. Nord Stud Alcohol Drugs 35:357-371. https://doi.org/10.1177/1455072518789852

69. Hernan MA, Robins JM (2020) Causal inference: what if. Chapman \& Hall/CRC, Boca Raton

70. Alin A (2010) Multicollinearity. Wiley Interdiscip Rev Comput Stat 2:370-374. https://doi.org/10.1002/wics.84

71. Caspi A, Bem DJ, Elder GH (1989) Continuities and consequences of interactional styles across the life course. J Pers 57:375-406. https://doi.org/10.1111/j.1467-6494.1989.tb00487.x

72. Bevilacqua L, Hale D, Barker ED, Viner R (2018) Conduct problems trajectories and psychosocial outcomes: a systematic review and meta-analysis. Eur Child Adolesc Psychiatry 27:1239-1260. https://doi.org/10.1007/s00787-017-1053-4

73. Farmer RF, Gau JM, Seeley JR, Kosty DB, Sher KJ, Lewinsohn PM (2016) Internalizing and externalizing disorders as predictors of alcohol use disorder onset during three developmental periods. Drug Alcohol Depend 164:38-46. https://doi.org/10. 1016/j.drugalcdep.2016.04.021

74. Hammerton G, Edwards AC, Mahedy L, Murray J, Maughan B, Kendler KS et al (2019) Externalising pathways to alcoholrelated problems in emerging adulthood. J Child Psychol Psychiatry. https://doi.org/10.1111/jcpp.13167

75. Kretschmer T, Hickman M, Doerner R, Emond A, Lewis G, Macleod J et al (2014) Outcomes of childhood conduct problem trajectories in early adulthood: Findings from the ALSPAC study. Eur Child Adolesc Psychiatry 23:539-549. https://doi.org/ 10.1007/s00787-013-0488-5

76. Moffitt TE, Caspi A, Harrington H, Milne BJ (2002) Males on the life-course-persistent and adolescence-limited antisocial 
pathways: follow-up at age 26 years. Dev Psychopathol 14:179207. https://doi.org/10.1017/S0954579402001104

77. Odgers CL, Moffitt TE, Broadbent JM, Dickson N, Hancox RJ, Harrington $\mathrm{H}$ et al (2008) Female and male antisocial trajectories: from childhood origins to adult outcomes. Dev Psychopathol 20:673-716. https://doi.org/10.1017/S09545794080003 33

78. Mold A (2017) 'Everybody Likes a Drink. Nobody Likes a Drunk'. Alcohol, health education and the public in 1970s Britain. Soc Hist Med 30:612-636. https://doi.org/10.1093/shm/ hkw094

79. Baggott R (1986) Alcohol, politics and social policy. J Soc Policy 15:467-488. https://doi.org/10.1017/S0047279400015506

80. Lader D, Steel M (2010) Drinking: adults' behaviour and knowledge in 2009: a report on research using the National Statistics Opinions (Omnibus) Survey produced on behalf of the NHS Information Centre for Health and Social Care. Office for National Statistics, London

81. Berg NJ, Kiviruusu OH, Lintonen TP, Huurre TM (2018) Longitudinal prospective associations between psychological symptoms and heavy episodic drinking from adolescence to midlife. Scand J Public Health. https://doi.org/10.1177/1403494818 769174

82. Soloski KL (2018) Self-medication hypothesis and family socialization theory: examining independent and common mechanisms responsible for binge drinking. Fam Process. https://doi.org/10. 1111/famp.12403

83. Colman I, Murray J, Abbott RA, Maughan B, Croudace TJ, Jones PB (2009) Outcomes of conduct problems in adolescence: 40 year follow-up of national cohort. Br Med J 338:208-211

84. Dubow EF, Boxer P, Huesmann LR (2008) Childhood and adolescent predictors of early and middle adulthood alcohol use and problem drinking: the Columbia County Longitudinal Study. Addiction 103:36-47

85. Mason WA, Hawkins JD, Kosterman R, Catalano RF (2010) Alcohol use disorders and depression: protective factors in the development of unique versus comorbid outcomes. J Child Adolesc Subst Abuse 19:309-323. https://doi.org/10.1080/1067828x. 2010.502491

86. Rhew IC, Fleming CB, Vander Stoep A, Nicodimos S, Zheng C, McCauley E (2017) Examination of cumulative effects of early adolescent depression on cannabis and alcohol use disorder in late adolescence in a community-based cohort. Addiction 112:1952-1960

87. Thompson KD, Leadbeater BJ, Ames ME (2015) Reciprocal effects of internalizing and oppositional defiance symptoms on heavy drinking and alcohol-related harms in young adulthood. Subst Abuse Res Treat 9:21-31

88. Edwards AC, Joinson C, Dick DM, Kendler KS, Macleod J, Munafo $M$ et al (2014) The association between depressive symptoms from early to late adolescence and later use and harmful use of alcohol. Eur Child Adolesc Psychiatry 23:1219-1230

89. Cook EC, Pflieger JC, Connell AM, Connell CM (2015) Do specific transitional patterns of antisocial behavior during adolescence increase risk for problems in young adulthood? J Abnorm Child Psychol 43:95-106. https://doi.org/10.1007/ s10802-014-9880-y

90. Ohannessian CM, Flannery KM, Simpson E, Russell BS (2016) Family functioning and adolescent alcohol use: a moderated mediation analysis. J Adolesc 49:19-27
91. Davoren MP, Demant J, Shiely F, Perry IJ (2016) Alcohol consumption among university students in Ireland and the United Kingdom from 2002 to 2014: a systematic review. BMC Public Health. https://doi.org/10.1186/s12889-016-2843-1

92. Caspi A, Houts RM, Belsky DW, Goldman-Mellor SJ, Harrington $\mathrm{H}$, Israel $\mathrm{S}$ et al (2014) The $p$ factor: one general psychopathology factor in the structure of psychiatric disorders? Clin Psychol Sci J Assoc Psychol Sci 2:119-137. https://doi.org/ 10.1177/2167702613497473

93. Martel MM, Pan PM, Hoffmann MS, Gadelha A, Do Rosário MC, Mari JJ et al (2017) A general psychopathology factor ( $p$ factor) in children: structural model analysis and external validation through familial risk and child global executive function. J Abnorm Psychol 126:137-148. https://doi.org/10.1037/abn00 00205

94. Carney R, Stratford B, Moore KA, Rojas A, Daneri MP (2015) What works for reducing problem behaviors in early childhood: lessons from experimental evaluations. Child Trends. https:// www.childtrends.org/publications/what-works-for-reducingproblem-behaviors-in-early-childhood. Accessed 18 Jan 2021

95. Fergusson DM, Horwood LJ, Ridder EM, Beautrais AL (2005) Subthreshold depression in adolescence and mental health outcomes in adulthood. Arch Gen Psychiatry 62:66-72. https://doi. org/10.1001/archpsyc.62.1.66

96. McLeod GFH, Horwood LJ, Fergusson DM (2016) Adolescent depression, adult mental health and psychosocial outcomes at 30 and 35 years. Psychol Med 46:1401-1412. https://doi.org/10. 1017/S0033291715002950

97. Fanti KA, Henrich CC (2010) Trajectories of pure and cooccurring internalizing and externalizing problems from age 2 to age 12: findings from the national institute of child health and human development study of early child care. Dev Psychol 46:1159-1175. https://doi.org/10.1037/a0020659

98. Sedgwick P (2014) Bias in observational study designs: prospective cohort studies. BMJ 349:g7731. https://doi.org/10.1136/bmj. g7731

99. Mostafa T, Narayanan M, Pongiglione B, Dodgeon B, Goodman A, Silverwood RJ et al (2020) Improving the plausibility of the missing at random assumption in the 1958 British birth cohort: a pragmatic data driven approach. UCL Centre for Longitudinal Studies, London

100. VanderWeele TJ, Ding P (2017) Sensitivity analysis in observational research: Introducing the E-value. Ann Intern Med 167(4):268

101. Zucker RA, Heitzeg MM, Nigg JT (2011) Parsing the undercontrol-disinhibition pathway to substance use disorders: a multilevel developmental problem. Child Dev Perspect 5(4):248-255

102. Aliev F, Wetherill L, Bierut L, Bucholz KK, Edenberg H, Foroud $\mathrm{T}$ et al (2015) Genes associated with alcohol outcomes show enrichment of effects with broad externalizing and impulsivity phenotypes in an independent sample. J Stud Alcohol Drugs 76(1):38-46

103. Dick DM, Agrawal A (2008) The genetics of alcohol and other drug dependence. Alcohol Res Health 31(2):111-118

104. Schulenberg JE, Maggs JL (2008) Destiny matters: distal developmental influences on adult alcohol use and abuse. Addiction 103(s1):1-6 